\title{
Poly(Ethylene Vinyl Acetate) (EVA)/Low Density Polyethylene (LDPE)/Ammonium Polyphosphate (APP) Composites Cross-linked by Dicumyl Peroxide for Wire and Cable Applications
}

\author{
By Jaroslav MOSNÁČEK, ${ }^{1,2}$ Ahmed A. BASFAR, ${ }^{2, *}$ Tariq M. SHUKRI, ${ }^{2}$ and Mohammed A. BAHATTAB ${ }^{3}$
}

\begin{abstract}
Formulations of chemically cross-linked poly(ethylene vinyl acetate) (EVA) and low density polyethylene (LDPE) blends containing intumescent flame retardant such as ammonium polyphosphate (APP) were prepared. Influence of polyethylene grafted with maleic anhydride (PEgMA), boric acid or combinations of them as well as various EVA/LDPE ratios on flammability, mechanical, thermal and electrical properties was investigated. Flame retardancy was found to be improved after addition of boric acid to APP formulations. On the other hand, mechanical properties decreased for formulations containing boric acid. Combination of boric acid with PEgMA gives formulations with good mechanical and thermal properties as well as good flame retardancy. Good thermal properties based on retention of mechanical properties after thermal aging were observed for all formulations due to introduction of cross-linking. All formulations show also good electrical properties.

KEY WORDS: Mechanical Properties / Flame Retardance / Ammonium Polyphosphate / Talc / Crosslinking /
\end{abstract}

Polyolefins due to their good mechanical properties, good resistance to chemicals and easy processing is used in many applications. However, they have some disadvantages such as low melting temperature, low thermal stability, high flammability as well as poor compatibility with additives. Compatibility of additives with polyolefins can be improved by addition of some compatibilizers or coupling agents. ${ }^{1}$ Thermal properties of polyolefins can be improved by small addition of stabilizers. A small quantity of processing stabilizers is usually added to prevent oxidative degradation of polyolefins caused by combined action of shear, heat and oxygen during their melt processing. Phenolic antioxidants are widely used as processing stabilizers for polyolefins. ${ }^{2,3}$ They act as scavengers of oxygen-centered alkoxy and peroxy radicals, but they are not able to provide long term heat stability. ${ }^{4}$

The flame retardancy of polyolefins on the other hand can be improved using flame retardants. There are several types of flame retardants which are used to improve flame retardancy of polyolefins. Recently, there is a trend to avoid use of halogenated flame retardants due to environmental and safety concerns. Thus, as main non-halogenated flame retardants, mainly metal hydroxides ${ }^{1,5-8}$ or intumescent flame retardant (IFR) systems ${ }^{9-16}$ are used. Very good efficiency in flame retardancy of polyolefins can be achieved using IFR systems. However a higher loading of IFR additive is needed than that of some halogen-containing flame retardants. This results in lowered mechanical properties of the flame-retardant materials. Thus, the flame retardant efficiency of IFR should be further improved. To improve the performance of IFR in polyolefins, synergistic agents such as boroxo siloxanes (products of reaction of poly siloxanes with boric acid), ${ }^{9,10}$ clays and nanoclays ${ }^{13,14}$ or some metal-containing compouds ${ }^{15,16}$ which can enhance the flame-retardant action of IFR can be used.

In recent work, ${ }^{17}$ current authors demonstrated that crosslinking can increase tensile strength of polyethylene/ammonium polyphosphate composites and thus, at reasonable yield of cross-linking, improve their mechanical properties. Moreover it gives improvement in thermal stability as well. ${ }^{17,18}$

In this paper various formulations containing EVA blended with LDPE and ammonium polyphosphate (APP) as an IFR were mixed with co-additives, stabilizer and cross-linking agents (see Table I) to develop LDPE/EVA/IFR composites with good mechanical and thermal properties and good flame retardancy. It is well known that presence of boron atom, from zinc borate or boroxosiloxanes, in combination with APP can improve action of APP in flame retardancy of polyolefins. Here the influence of boric acid in polyolefin/APP formulations on flammability as well as mechanical, thermal and electrical properties was investigated.

\section{EXPERIMENTAL}

\section{Materials}

LDPE HP2022J from SABIC (Jubail, Saudi Arabia), EVA Alcudia PA-538 with 18 weight $\%$ of vinyl acetate from REPSOL YPF (Madrid, Spain) were used as received. Antioxidant, Irganox 1010 from Ciba Specialty Chemicals (Basel, Switzerland); processing aid, paraffin wax from Fluka Chemi-

\footnotetext{
${ }^{1}$ Polymer Institute, Slovak Academy of Sciences, Dúbravská cesta 9, 84236 Bratislava, Slovak Republic

${ }^{2}$ Radiation Technology Center, Atomic Energy Research Institute, King Abdulaziz City for Science and Technology, P.O. Box 6086, Riyadh 11442, Saudi Arabia

${ }^{3}$ Petroleum and Petrochemicals Research Institute, King Abdulaziz City for Science and Technology, P.O.Box 6086, Riyadh 11442, Saudi Arabia

*To whom correspondence should be addressed (Tel: +9661-4813648, Fax: +9661-4813640, E-mail: abasfar@kacst.edu.sa).
} 
Table I. Prepared formulations

\begin{tabular}{ccrcccc}
\hline $\begin{array}{c}\text { Formulation } \\
\text { Code* }\end{array}$ & LDPE & EVA & $\begin{array}{c}\text { APP } \\
\text { (phr) }\end{array}$ & $\begin{array}{c}\text { Talc } \\
\text { (phr) }\end{array}$ & $\begin{array}{c}\text { PEgMA } \\
\text { (phr) }\end{array}$ & $\begin{array}{c}\text { Boric acid } \\
\text { (phr) }\end{array}$ \\
\hline C-1 & 60 & 40 & 35 & 1 & 3 & - \\
C-2 & 40 & 60 & 35 & 1 & 3 & - \\
C-3 & 20 & 80 & 35 & 1 & 3 & - \\
C-4 & - & 100 & 35 & 1 & 3 & - \\
C-5 & 60 & 40 & 35 & 1 & - & 1.5 \\
C-6 & 40 & 60 & 35 & 1 & - & 1.5 \\
C-7 & 20 & 80 & 35 & 1 & - & 1.5 \\
C-8 & - & 100 & 35 & 1 & - & 1.5 \\
C-9 & 60 & 40 & 35 & 1 & 1.5 & 1.5 \\
C-10 & 40 & 60 & 35 & 1 & 1.5 & 1.5 \\
C-11 & 20 & 80 & 35 & 1 & 1.5 & 1.5 \\
C-12 & - & 100 & 35 & 1 & 1.5 & 1.5 \\
\hline
\end{tabular}

*All formulations contain also $0.3 \mathrm{phr}$ of Irganox $1010,0.3 \mathrm{phr}$ of paraffin wax and 3 phr of DCP.

cal Co. (Steinheim, Germany); flame retardant based on ammonium polyphosphate, Exolit AP765 ( 21 weight $\%$ of phosphorus; $\sim 18$ weight $\%$ of nitrogen; decomposition temperature $>275^{\circ} \mathrm{C}$; density $\sim 1.75 \mathrm{~kg} / \mathrm{l}$; bulk density $\sim 0.6$ $\mathrm{kg} / \mathrm{l}$ ) from Clariant (Sulzbach, France); PEgMA 12031 from Solvay Co. (Brussels, Belgium); boric acid from Brenntag (Mulheim, Germany); talc V 3837 from Luzenac (Toulouse, France); cross-linking agent, dicumyl peroxide Perkadox BC40K from Akzo Nobel (Arnhem, The Netherlands), all were used as received.

\section{Compounding and Crosslinking}

All additives except dicumyl peroxide were mixed with resins for $10 \mathrm{~min}$ at $150{ }^{\circ} \mathrm{C}$ using an internal mixer (Model 350 S) from Brabender Co., Duisburg, Germany with speed of $50 \mathrm{rpm}$. Then the mixture was moved to two-roll-mill from Brabender Co., Duisburg, Germany and dicumyl peroxide was added at $110^{\circ} \mathrm{C}$ and mixed for $3-5 \mathrm{~min}$. Cross-linking was performed by molding sheets for $30 \mathrm{~min}$ at $170^{\circ} \mathrm{C}$. Sheets with thickness $2 \mathrm{~mm}$ were prepared and used for all testing methods.

\section{Testing Methods}

Tensile strength and elongation at break before and after aging were measured using a universal testing machine from Instron Co., Canton Massachusetts, USA in accordance with ASTM D 638M (using speed $50 \mathrm{~mm} / \mathrm{min}$ ).

Flammability of prepared formulations was characterized by UL94 and limiting oxygen index (LOI) flammability tests as well as by Cone calorimeter. UL94 flammability tests were performed using a flammability chamber from CEAST Co., Italy in accordance with ASTM D635 for horizontal and ASTM D3801 for vertical position. LOI test was performed using an apparatus from Fire Testing Technology Limited (Incorporating Stanton Redcroft), UK in accrodance with ISO 4589 (ASTM D2863). Cone calorimeter from Fire Testing Technology Limited (Incorporating Stanton Redcroft), UK was used to measure heat release inaccordance with ASTM 1354$04 \mathrm{a}$ under a heat flux of $50 \mathrm{~kW} / \mathrm{m}^{2}$ which corresponds to the heat evolved during a fire.
Thermal aging of samples was performed at $135^{\circ} \mathrm{C}$ for $168 \mathrm{~h}$ using a heat aging oven in accordance with IEC 60811-1-2.

Volume resistivity was measured using a high resistance meter, Model HP4339B in accordance with ASTM D257-99.

\section{RESULTS AND DISCUSSION}

\section{Mechanical Properties}

To achieve good mechanical properties, a good compatibility of additives with resin is very important. Recently ${ }^{17}$ we found PEgMA to be better compatibilizer than vinyl silane in LDPE/EVA/APP composites. Therefore, here we decided to use PEgMA to increase compatibility of additives with the resins. Because of polar groups presented in EVA, higher EVA content could help to improve the compatibility as well. Therefore, various ratios of LDPE and EVA were also studied. At the same time a small amount of talc was used in all formulations in order to achieve higher tensile strength. ${ }^{17}$

Tensile strength of prepared formulations is shown in Figure 1 and Table II. Generally, addition of additives to a resin leads to a decrease in tensile strength. As listed in Table II, tensile strength of prepared APP formulations depends strongly on co-additives, such as boric acid and PEgMA, although they are used only in a small quantity. The tensile strength of the formulations containing only PEgMA (C1-C4) changes between 14 and $16 \mathrm{MPa}$ and the highest value was achieved for formulation of pure EVA as a base resin. This value is quite close to the tensile strength $18.5 \mathrm{MPa}$ measured for a pure EVA without any additives. However, there are only slight differences with increase of EVA content in these formulations. Thus, good compatibility of additives with the resins is achieved also at the lowest investigated EVA content. On the other hand, small amount of polar additive such as boric acid leads to significant decrease of tensile strength. Thus, in the case of formulations containing boric acid without PEgMA (C5-C8), the tensile strength was significantly lower over the range 11-13 MPa. Addition of small amount of PEgMA to the formulations containing boric acid has almost no influence on the tensile strength in the cases when LDPE is

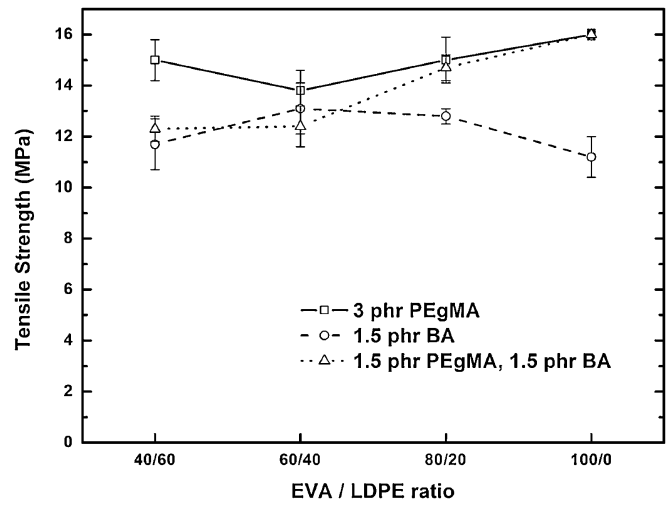

Figure 1. Tensile strength of chemically cross-linked EVA/LDPE/APP formulations with various additives: PEgMA (codes C-1 to C-4), boric acid (codes $\mathbf{C}-\mathbf{5}$ to $\mathbf{C}-\mathbf{8}$ ), and combination of PEgMA and boric acid (codes $\mathbf{C}-\mathbf{9}$ to $\mathbf{C - 1 2}$ ) as a function of EVA/LDPE ratio. 
Table II. Mechanical properties as well as retention of mechanical properties after thermal aging of prepared formulations

\begin{tabular}{|c|c|c|c|c|c|c|}
\hline $\begin{array}{l}\text { Formulation } \\
\text { Code }\end{array}$ & TS (MPa) & Eb (\%) & $\begin{array}{c}\text { TS after } \\
\text { aging (MPa) }\end{array}$ & $\begin{array}{l}\text { Retention } \\
\text { of TS (\%) }\end{array}$ & $\begin{array}{c}\text { Eb after } \\
\text { aging (\%) }\end{array}$ & $\begin{array}{c}\text { Retention of } \\
\text { Eb (\%) }\end{array}$ \\
\hline LDPE & $11.9 \pm 0.7$ & $496 \pm 30$ & - $^{*}$ & - $^{*}$ & - $^{*}$ & - $^{*}$ \\
\hline EVA & $18.5 \pm 0.9$ & $736 \pm 32$ & —* & 一 $^{*}$ & —* & — $^{*}$ \\
\hline C-1 & $15 \pm 0.8$ & $481 \pm 10$ & $14.2 \pm 1.0$ & 95 & $468 \pm 30$ & 97 \\
\hline C-2 & $13.8 \pm 0.8$ & $488 \pm 40$ & $12.2 \pm 0.6$ & 88 & $496 \pm 13$ & 102 \\
\hline C-3 & $15 \pm 0.9$ & $524 \pm 13$ & $14 \pm 0.6$ & 93 & $519 \pm 24$ & 99 \\
\hline C-4 & $16 \pm 0.1$ & $532 \pm 10$ & $15.4 \pm 0.5$ & 96 & $533 \pm 10$ & 100 \\
\hline C-5 & $11.7 \pm 1$ & $465 \pm 39$ & $10 \pm 0.5$ & 85 & $440 \pm 5.7$ & 95 \\
\hline C-6 & $13.1 \pm 1$ & $489 \pm 19$ & $13 \pm 0.8$ & 99 & $496 \pm 15$ & 101 \\
\hline C-7 & $12.8 \pm 0.3$ & $443 \pm 17$ & $10.8 \pm 0.5$ & 84 & $417 \pm 33$ & 94 \\
\hline C-8 & $11.2 \pm 0.8$ & $396 \pm 37$ & $11 \pm 0.9$ & 98 & $391 \pm 20$ & 99 \\
\hline C-9 & $12.3 \pm 0.5$ & $475 \pm 14$ & $11.5 \pm 0.5$ & 93 & $459 \pm 16.5$ & 97 \\
\hline C-10 & $12.4 \pm 0.8$ & $501 \pm 24$ & $11 \pm 1.2$ & 89 & $460 \pm 25$ & 92 \\
\hline C-11 & $14.7 \pm 0.5$ & $564 \pm 22$ & $14 \pm 0.4$ & 95 & $535 \pm 2.4$ & 95 \\
\hline C-12 & $16 \pm 0.2$ & $542 \pm 26$ & $14.7 \pm 0.7$ & 92 & $523 \pm 25$ & 96 \\
\hline
\end{tabular}

*Samples were destroyed during thermal aging

mixed with EVA with almost the same ratio. On the other hand, addition of small amount of PEgMA can improve compatibility of formulations where percentage of EVA increases (C9-C12). Thus, for the resin ratios EVA/LDPE 80/20 and 100/0, the formulations containing boric acid together with PEgMA achieved comparable values of tensile strength as the formulations without boric acid and very close to tensile strength of pure EVA.

The addition of additives to a resin generally decreases elongation at break. Addition of $35 \mathrm{phr}$ APP to EVA led to about $200 \%$ reduction in the elongation at break after crosslinking (see Table II). However, most of prepared APP formulations have elongation at break higher than those of pure LDPE resin. As described below, besides the formulations containing boric acid without PEgMA, there are no significant differences among prepared formulations without some significant increase in elongation at break with increase of EVA content, thus confirming a good compatibility of additives with the resins. Therefore, it is worthy to say that the decrease in elongation at break for these formulations in comparison with pure EVA is mainly due to cross-linking.

From comparison among prepared formulations, a slight increase in elongation at break can be observed in formulations containing only PEgMA without boric acid (C1-C4) with increase of EVA percentage (see Figure 2 and Table II). On the other hand, in the formulations containing boric acid without PEgMA (C5-C8), an increase of EVA content is accompanied, without any logical reason, by a decrease in elongation at break. Addition of PEgMA into the formulations containing boric acid (C9-C12) increased the elongation at break due to better compatibility of boric acid with the resin.

As seen from these measurements, most of the prepared cross-linked composites have tensile strength and elongation at break similar to those of pure LDPE and pure EVA resins. Although, the addition of boric acid to polyolefin/APP formulations can deteriorate mechanical properies, a small amount of compatibilizer such as PEgMA can improve the compatibility of boric acid to the composite and retains good mechanical properties of polyolefin/APP composites.

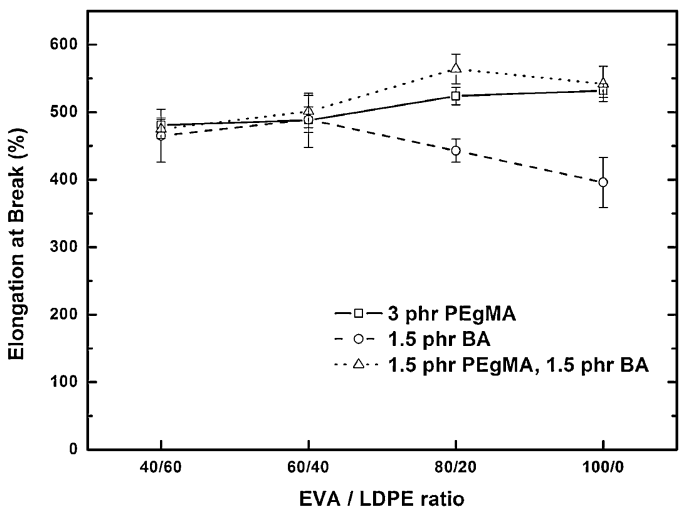

Figure 2. Elongation at break of chemically cross-linked EVA/LDPE/APP formulations with various additives: PEgMA (codes $\mathbf{C}-\mathbf{1}$ to $\mathbf{C}-\mathbf{4}$ ), boric acid (codes $\mathbf{C}-\mathbf{5}$ to $\mathbf{C - 8}$ ), and combination of PEgMA and boric acid (codes $\mathbf{C}-\mathbf{9}$ to $\mathbf{C - 1 2}$ ) as a function of EVA/LDPE ratio.

\section{Flammability}

Recently, ${ }^{19,20}$ the interactions between boric acid and ammonium polyphosphates during heating were studied by various methods. It was found that APP and boric acid interact upon heating. It has been shown that boric acid turns into boron oxide first, which then reacts at higher temperature with phosphoric acid to form borophosphates. It is suggested that the formation of boron oxides and borophosphates is responsible for the development of a hard and mechanically resistant intumescent char with a good thermal stability. Mixing of both components into a resin is therefore expected to lead to a synergism in flame retardancy.

Flammability of prepared formulations was tested by three various methods. Unlike pure LDPE and EVA, all investigated formulations passed the UL94 horizontal burning test and achieved V0 rating in UL94 vertical burning test. The results from UL94 test show very good flame retardancy for all formulations. For further evaluation of flame retardancy, as this method doesn't show the differences among the formulations, LOI measurements were performed as well.

As shown from Table III and Figure 3, addition of $35 \mathrm{phr}$ APP to EVA/LDPE blend followed by chemical cross-linking 
Table III. Flammability of prepared formulations based on LO and cone calorimeter measurements

\begin{tabular}{|c|c|c|c|c|c|}
\hline $\begin{array}{l}\text { Formulation } \\
\text { Code }\end{array}$ & $\begin{array}{l}\text { LOI } \\
\text { (\%) }\end{array}$ & $\begin{array}{c}\text { THR* } \\
\left(\mathrm{MJ} / \mathrm{m}^{2}\right)\end{array}$ & $\begin{array}{l}\text { TTI } \\
\text { (s) }\end{array}$ & $\begin{array}{c}\text { PHRR } \\
\left(\mathrm{kW} / \mathrm{m}^{2}\right)\end{array}$ & $\begin{array}{c}\text { TPHRR } \\
\text { (s) }\end{array}$ \\
\hline LDPE & 18.0 & 2.76 & 43 & 666 & 95 \\
\hline EVA & 19.0 & 2.52 & 33 & 803 & 80 \\
\hline C-1 & 28.7 & 2.46 & 51 & 374 & 100 \\
\hline C-2 & 28.1 & 2.62 & 53 & 376 & 110 \\
\hline C-3 & 28.7 & 3.02 & 50 & 434 & 120 \\
\hline C-4 & 29.3 & 2.94 & 54 & 493 & 115 \\
\hline C-5 & 29.4 & 2.44 & 49 & 309 & 100 \\
\hline C-6 & 29.5 & 2.45 & 49 & 354 & 110 \\
\hline C-7 & 31.2 & 2.63 & 48 & 372 & 125 \\
\hline C-8 & 32.0 & 3.05 & 47 & 422 & 110 \\
\hline C-9 & 29.6 & 2.50 & 50 & 323 & 110 \\
\hline C-10 & 29.0 & 2.69 & 48 & 362 & 120 \\
\hline C-11 & 31.5 & 2.52 & 50 & 400 & 125 \\
\hline C-12 & 32.0 & 2.67 & 48 & 350 & 105 \\
\hline
\end{tabular}

*Values are normalized to $1 \mathrm{~g}$ of a tested material.

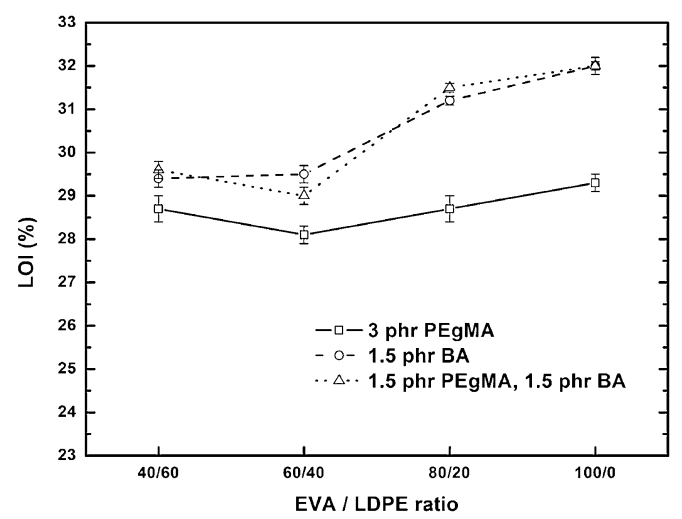

Figure 3. LOI (\%) of chemically cross-linked EVA/LDPE/APP formulations with various additives: PEgMA (codes $\mathbf{C}-\mathbf{1}$ to $\mathbf{C}-\mathbf{4}$ ), boric acid (codes $\mathbf{C}-\mathbf{5}$ to $\mathbf{C - 8}$ ), and combination of PEgMA and boric acid (codes $\mathbf{C}-\mathbf{9}$ to $\mathbf{C - 1 2}$ ) as a function of EVA/LDPE ratio.

leads to an increase in LOI up to about $28 \%$ compared to $18 \%$ or $19 \%$ for pure LDPE and pure EVA, respectively. Moreover, as described below, LOI strongly depends on the composition of prepared formulations and can be further increased by addition of boric acid and by change of EVA content.

As shown in Figure 3, the LOI (\%) of formulations containing PEgMA without boric acid (C-1 to C-4) are between $28-29.3 \%$. There is only slight increase in LOI (\%) with increase of EVA content. Addition of boric acid to polyolefin/ APP formulations increases flame retardancy as shown in Figure 3 . LOI (\%) of formulations containing boric acid without PEgMA (C-5 to C-8) change from $29.5 \%$ for formulations with lower content of EVA up to $32 \%$ for formulations containing only EVA as a base resin. The improved flame retardancy in the presence of boric acid confirms the synergistic action of boron with phosphates similarly like it was described in polypropylene/phosphates formulations after addition of zinc borate or boroxosilanes.9,10 Addition of a small amount of PEgMA in order to increase compatibility of boric acid and improve the mechanical properties of the formulations containing boric acid has no influence on the flame retardancy. LOI (\%) of boric

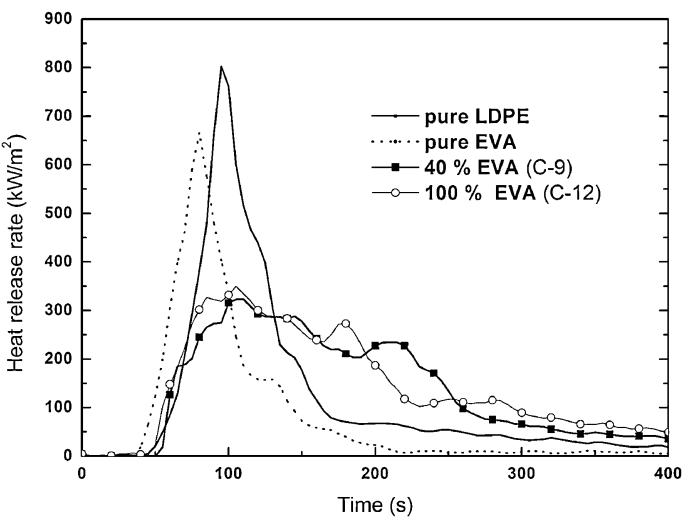

Figure 4. Heat release rate of pure LDPE, pure EVA and EVA/LDPE/APP formulations containing combination of PEgMA and boric acid with two various EVA/LDPE ratios (40/60 and 100/0) (C-9 and C-12, respectively) as a function of burning time.

acid after addition of PEgMA are for all EVA/LDPE blends almost the same as LOI $(\%)$ of boric acid formulations without PEgMA. Thus, PEgMA has no influence on the synergism between boric acid and APP.

Some more information about dynamic flammability of prepared formulations can be gained from measurement of heat release. Although the total heat release (THR) of all prepared flame retardant composites is almost the same like for pure LDPE and EVA resins, addition of APP flame retardant completely changes the course of the burning (see Table III). First, time to ignition (TTI) increases from 43 and $33 \mathrm{~s}$ for pure LDPE and pure EVA, respectively, up to about $50 \mathrm{~s}$ for all EVA/LDPE formulations containing $35 \mathrm{phr}$ of APP. After ignition, there are high sharp peaks of heat release rate for pure LDPE and EVA (see Figure 4), however after addition of flame retardant this peak of heat release rate decreases followed by a plateau which is a characteristic for intumescent layer formed shortly after ignition. After the destruction of intumescent layer, the second peak in heat release rate is observed. Thus, as seen from Table III, a peak in heat release rate (PHRR) decreases to about half of pure LDPE or EVA for all prepared APP formulations. Moreover, an increase of time to peak in heat release rate (TPHRR) for APP flame retardant formulations of about 20-30s in comparison with pure EVA and LDPE resins is observed. Addition of only small amount of boric acid or PEgMA to APP flame retarded composites has no influence on the course of heat release. Thus almost the same course of heat release rate is observed for formulations containing PEgMA, boric acid or combination of them, when formulations with the same EVA content are compared. On the other hand, the time to second maximum of heat release rate decreases as EVA content increases (see Figure 4), similarly as described recently for LDPE/EVA/PEgMA composites containing $30 \mathrm{phr}$ of APP. ${ }^{21}$ Thus, EVA changes the properties of intumescent layer causing its lower stability and earlier destruction.

Slight increase in total heat release with increase of EVA content is observed for formulations containing PEgMA and/or boric acid alone (C-1 to $\mathbf{C - 8}$ ). For formulations containing combination of PEgMA and boric acid (C-9 to C-12), the total 
Table IV. Volume resistivity of prepared formulations

\begin{tabular}{|c|c|c|c|c|}
\hline \multirow[b]{2}{*}{ Resin ratio } & \multicolumn{4}{|c|}{ Volume resistivity $(\Omega \cdot \mathrm{cm})$} \\
\hline & EVA/LDPE & EVA/LDPE & EVA/LDPE & EVA/LDPE \\
\hline Co-additive & $40 / 60$ & $60 / 40$ & $80 / 20$ & $100 / 0$ \\
\hline PEgMA (3 phr) & $1.44 \times 10^{16}$ & $1.21 \times 10^{16}$ & $1.67 \times 10^{16}$ & $1.39 \times 10^{16}$ \\
\hline Boric acid (1.5 phr) & $1.47 \times 10^{16}$ & $0.79 \times 10^{16}$ & $1.02 \times 10^{16}$ & $0.80 \times 10^{16}$ \\
\hline $\begin{array}{l}\text { PEgMA + boric acid } \\
(1.5 \mathrm{phr}+1.5 \mathrm{phr})\end{array}$ & $0.84 \times 10^{16}$ & $1.02 \times 10^{16}$ & $1.14 \times 10^{16}$ & $0.81 \times 10^{16}$ \\
\hline
\end{tabular}

Note: Volume resistivity of pure LDPE and pure EVA is $2.29 \times 10^{16}$ and $0.93 \times 10^{16}$, respectively.

heat release is almost the same for all investigated EVA/LDPE blends.

\section{Thermal Stability}

Thermal stability of developed formulations was characterized by retention of tensile strength and elongation at break after thermal aging at $135^{\circ} \mathrm{C}$ for $168 \mathrm{~h}$. Unlike the uncrosslinked pure LDPE and EVA resins, which were destroyed during thermal aging, all prepared cross-linked formulations have good mechanical properties even after thermal aging. As seen from Table II, all the prepared formulations exhibit very good retention of tensile strength of $100 \pm 15 \%$. In addition, elongation at break, which is much more sensitive to thermal aging, has very good retention values of $100 \pm 10 \%$ for all prepared formulations.

\section{Electrical Properties}

Volume resistivity for most of formulations was investigated as well (see Table IV). Pure LDPE has generally very good electrical properties. Little lower volume resistivity is observed for pure EVA. Generally for filled cross-linked LDPE material used for cable insulations (usually used for $0.6 / 1 \mathrm{kV}$ cables) the volume resistivity should be at least of order $10^{14} \Omega \mathrm{cm}$. As shown in Table IV, all investigated cross-linked formulations have volume resistivity almost of the same order as pure LDPE (i.e., $10^{16}$ ). Thus developed formulations have acceptable volume resistivity as required for cable insulation material.

\section{CONCLUSIONS}

EVA/LDPE crosslinked composites with high flame retardancy were prepared by combination of ammonium polyphosphate with small amount of boric acid. By this combination increase in LOI up to $32 \%$ can be achieved. Good mechanical properties of the EVA/LDPE/APP formulations containing boric acid can be achieved after addition of small amount of PEgMA, which can improve compatibility of boric acid to the composites. On the other hand, the presence of PEgMA has no influence on the flame retardancy as well as thermal stability and electrical properties of EVA/LDPE/APP formulations containing boric acid.

Acknowledgment. The authors would like to extend their deep appreciation to The Government of Saudi Arabia represented by Ministry of Finance for funding this project.
Thanks are also extended to King Abdulaziz City for Science and Technology (KACST) for providing logistic support to the project. Appreciation is also extended to Saudi Arabian Basic Industries Corporation (SABIC), Riyadh Cables Co., and Saudi Cables Co. for providing technical information, resins and various additives.

Received: September 30, 2007

Accepted: February 3, 2008

Published: April 2, 2008

\section{REFERENCES}

1. J. E. Vostovich, U. S. Patent 4459380 (1984).

2. H. Zweifel, in "Plastics additives handbook" 5th ed., Hanser Publisher, Munich, 2001.

3. W. O. Drake, J. R. Pauqet, R. V. Todesco, and H. Zweifel, Angew. Makromol. Chem., 176, 215 (1990).

4. J. Pospísil, in "Oxidation inhibition in organic materials" vol. 1, chapter 3, J. Pospísil and P. P. Klemchuk, Ed., CRC Press, Boca Raton, 1990.

5. C. Scelza and A. Zaopo, U. S. Patent 6797200 (2004).

6. Q. S. Li, L. Q. Wang, and L. L. Liu, J. Polym. Mater., 15, 215 (1998).

7. J. A. Zhang, L. Q. Wang, and Q. S. Li, J. Wuhan. Univ. Technol., 14, 23 (1999).

8. L. Haurie, A. I. Fernández, J. I. Velasco, J. M. Chimenos, J.-M. L. Cuesta, and F. Espiell, Polym. Degrad. Stab., 91, 989 (2006).

9. P. Anna, G. Marosi, S. Bourbigot, M. Le Bras, and R. Delobel, Polym. Degrad. Stab., 77, 243 (2002).

10. G. Marosi, A. Marton, P. Anna, G. Bertalan, B. Marosfoi, and A. Szep, Polym. Degrad. Stab., 77, 259 (2002).

11. L. R. M. Estevao, M. Le Bras, R. Delobel, and R. S. V. Nascimento, Polym. Degrad. Stab., 88, 444 (2005).

12. Y. Tang, Y. Hu, B. G. Li, L. Liu, Z. Z. Wang, Z. Y. Chen, and W. C. Fan, J. Polym. Sci., Part A: Polym. Chem., 42, 6163 (2004).

13. G. Marosi, A. Márton, A. Szép, I. Csontos, S. Keszei, E. Zimonyi, A. Tóth, X. Almeras, and M. Le Bras, Polym. Degrad. Stab., 82, 379 (2003).

14. S. Bourbigot, M. Le Bras, S. Duquesne, and M. Rochery, Macromol. Mater. Eng., 289, 499 (2004).

15. M. Lewin and E. Makoto, Polym. Adv. Technol., 14, 3 (2003).

16. F. Xie, Y.-Z. Wang, B. Yang, and Y. Liu, Macromol. Mater. Eng., 291, 247 (2006).

17. A. A. Basfar, J. Mosnáček, T. M. Shukri, M. A. Bahattab, P. Noireaux, and A. Courdreuse, J. Appl. Polym. Sci., 107, 642 (2008).

18. D. Hashimoto, M. Nishiguchi, K. Iwata, and K. Saito, U. S. Patent 6 627819 (2003).

19. M. Jimenez, S. Duquesne, and S. Bourbigot, Termochim. Acta, 449, 16 (2006).

20. M. Jimenez, S. Duquesne, and S. Bourbigot, Surf. Coat. Technol., 201, 979 (2006).

21. T. M. Shukri, J. Mosnáček, A. A. Basfar, M. A. Bahattab, P. Noireaux, and A. Courdreuse, J. Appl. Polym. Sci., submitted. 